\title{
Evaluation of Relationship between Water Absorption and Durability of Concrete Materials
}

\author{
S. P. Zhang and L. Zong \\ Department of Civil Engineering and Architecture, Nanjing Institute of Technology, Nanjing 211167, China \\ Correspondence should be addressed to S. P. Zhang; zhangshiping1982@gmail.com
}

Received 6 January 2014; Revised 18 March 2014; Accepted 18 March 2014; Published 10 April 2014

Academic Editor: Juan José del Coz Díaz

Copyright ( 2014 S. P. Zhang and L. Zong. This is an open access article distributed under the Creative Commons Attribution License, which permits unrestricted use, distribution, and reproduction in any medium, provided the original work is properly cited.

\begin{abstract}
Environment has significant effects on the water absorption of concrete materials. This paper presents an experimental study of the influence of water absorption on the durability of concrete materials. A detailed analysis is also presented in order to establish useful relationship between them. Concrete specimens of different water absorption were prepared through different curing conditions, and results indicated that curing condition can significantly affect the surface water absorption. SEM photos also showed that different curing conditions caused different microstructure. After 28-days curing, compressive strength, permeability, sulfate attack, and chloride ion diffusion of concrete samples were investigated. As a result, both of surface sorptivity and internal sorptivity have no clear relationship with compressive strength. Results obtained also showed that only surface water absorption related to the performance of concrete including permeability, sulfate attack, and chloride ion diffusion. In addition, both impermeability and resistance to sulfate attack were linearly associated with surface sorptivity, and both correlation coefficients were not less than 0.9 . Furthermore, chloride ion diffusion coefficient has exponent relation to surface water absorption with higher correlation coefficient. However, no apparent relationship was found between internal water absorption and durability like impermeability, resistance to sulfate attack, and chloride ion diffusion.
\end{abstract}

\section{Introduction}

Durability of concrete plays a critical role in controlling its serviceability. Furthermore, durability of concrete is mainly dependent on the capacity of a fluid to penetrate the concrete's microstructure, which was called permeability. High permeability led to the introduction of molecules that react and destroy its chemical stability [1]. Moreover, low permeability of concrete can improve resistance to the penetration of water, sulphate ions, chloride ions, alkali ions, and other harmful substances which caused chemical attack [2]. Concrete permeability had a close relationship with the characteristics of its pore structure in the cement paste and the intensity of microcracks at the aggregate-cement paste interface as well as within the paste itself [3]. Here, pore structure mainly involved volume and size of the interconnected capillary pores. As we know, the hydration reaction of cement results in a product consisting of solid and pore systems. The pore network of a cement paste matrix provides passage for the transport of fluid into concrete and its development depends on a number of factors including the properties and composition of the concrete constituent materials, the initial curing condition and its duration, the age at testing, and the climatic exposure during drying and conditioning of the concrete $[4,5]$. The temperature of curing and the duration of moist curing are the key factors for proper pore structure. The effectiveness of initial curing becomes more important when mineral admixtures like fly ash are used as partial substitution for cement in concrete. Numerous workers have reported that mineral admixtures require a relatively long curing period for the favourable pozzolanic effect on the performance of concrete to be realized $[6,7]$.

Sorptivity is an index of moisture transport into unsaturated specimens, and recently it has also been recognized as an important index of concrete durability [8]. During sorptivity process, the driving force for water ingress into concrete is capillary suction within the pore spaces of concrete, and not a pressure head [9]. A detailed characterisation of the pore 




FIGURE 1: Sorptivity testing.

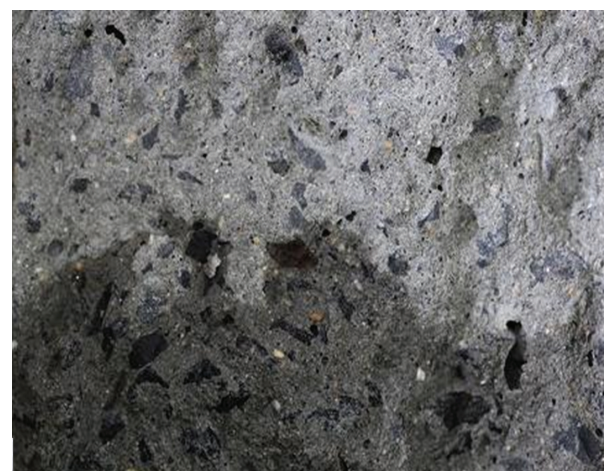

Figure 2: Permeability height of concrete.

structure of the concrete can be analyzed by many kinds of techniques, but the advanced methods are cumbersome and are neither available nor useful for daily concrete practice [3]. Sorptivity testing is also more representative of typical field conditions. Some experts have suggested that the method can also be used to measure the total pore volume of capillary and gel pores in the concrete [10]. Martys and Ferraris have shown that the sorptivity coefficient is essential to predict the service life of concrete as a structural material and to improve its performance [11]. The water absorption by immersion is also considered to be a relevant parameter about the performance of concrete. Several experimental investigations have shown that the capillary permeability is substantially affected by the curing condition [12]. Sufficient curing is essential for a concrete to provide its potential performance [13].

Theoretical relations between sorptivity and permeability are established in the literature $[14,15]$. However, these relations have not been extensively evaluated experimentally. In this study, the total capillary and gel pore volume was not measured directly but was estimated using the water uptake from soaking testing. The main objective of the present work is to study the effect of water absorption on durability of concrete such as compressive strength, permeability, sulfate attack, and chloride diffusion. Within these tests, mechanical test, impermeability test, sulfate attack test, and chloride migration tests are realized. A detailed analysis is also presented in order to establish useful relationship between these parameters.

\section{Materials and Methods}

2.1. Materials. In experimental studies, the OPC 42.5 was used. The chemical composition of this cement is given
TABLE 1: Chemical composition of cement.

\begin{tabular}{lccccccc}
\hline \multirow{2}{*}{ Sample } & \multicolumn{7}{c}{ Chemical composition (\%) } \\
& $\mathrm{CaO}$ & $\mathrm{SiO}_{2}$ & $\mathrm{Al}_{2} \mathrm{O}_{3}$ & $\mathrm{Fe}_{2} \mathrm{O}_{3}$ & $\mathrm{MgO}$ & $\mathrm{SO}_{3}$ & $\mathrm{Na}_{2} \mathrm{Oeq}$ \\
\hline Cement & 63.6 & 23.74 & 5.56 & 3.96 & 1.45 & 0.71 & 0.45 \\
\hline
\end{tabular}

TABLE 2: Mix proportions of concrete $\left(\mathrm{Kg} / \mathrm{m}^{3}\right)$.

\begin{tabular}{lccccc}
\hline Number & Cement & Sand & Crushed stone & Water & Admixture \\
\hline $\mathrm{A}$ & 420 & 635 & 1149 & 168 & 5.21 \\
$\mathrm{~B}$ & 420 & 635 & 1149 & 189 & 5.21 \\
\hline
\end{tabular}

at Table 1. The crushed stone aggregates and quartz sand with a fineness modulus of 2.4 were used in tests. The maximum particle size of aggregates is $20 \mathrm{~mm}$. As a result of experiments, the specific gravities of sand and crushed stone are 2650 and 2800, respectively. Concrete admixture used was polycarboxylate water reducers.

2.2. Methods. All concrete mixtures were prepared in the laboratory. Two kinds of water to cement ratio $(w / c)$ were used, and the detailed mixture proportions of the concrete studied are given in Table $2.100 \times 100 \times 100 \mathrm{~mm}$ cubes were cast to determine the compressive strength, respectively. Cores of $\Phi 175 \times \Phi 185 \times 150 \mathrm{~mm}$ were prepared for permeability test, and $100 \Phi \times 175 \mathrm{~mm}$ concrete cylinders were also prepared for chloride ions diffusion testing. All specimens were cast in steel molds and compacted using a vibrating table.

In order to achieve different water absorption, specimens were subjected to different curing methods as follows: Curing a: specimens were submerged in water $\left(20 \pm 3^{\circ} \mathrm{C}\right)$ after demoulding until testing; Curing b: after demoulding, specimens were cured in air condition $\left(20 \pm 3^{\circ} \mathrm{C}, \mathrm{RH} 90 \pm 5 \%\right)$ until testing; Curing c: specimens were cured in air condition $\left(20 \pm 3^{\circ} \mathrm{C}\right.$, RH $\left.60 \pm 5 \%\right)$ until testing; Curing d: specimens were submerged in water for 7 days after demoulding and subsequently placed in air conditions $\left(20 \pm 3^{\circ} \mathrm{C}, \mathrm{RH} 90 \pm 5 \%\right)$ until testing; Curing e: specimens were submerged in water for 7 days after demoulding and subsequently placed in air conditions $\left(20 \pm 3^{\circ} \mathrm{C}\right.$, RH $\left.60 \pm 5 \%\right)$ until testing.

Sorptivity of concrete was evaluated by penetration height and water absorption, and the introduction of this testing method was shown in Figure 1. All of these samples were dried at $60^{\circ} \mathrm{C}$ for $24 \mathrm{~h}$ to minimize damage to the microstructure from excessive drying. For penetration height, the surface with a length of $3-5 \mathrm{~mm}$ of the sample was in contact with water, as shown in Figure 1. Since the surface of the sample became dark when it absorbed water, penetration height at the side of samples was observed during testing. For water absorption, the surface and middle segments were cut from samples, respectively, and thus surface water absorption and internal water absorption were also measured. Before testing, specimens were sealed on the top and sides and placed in a water bath so that the open bottom was constantly submerged in a depth of 3-5 mm. Weight of samples was measured after 4 days, and water absorption was measured. 


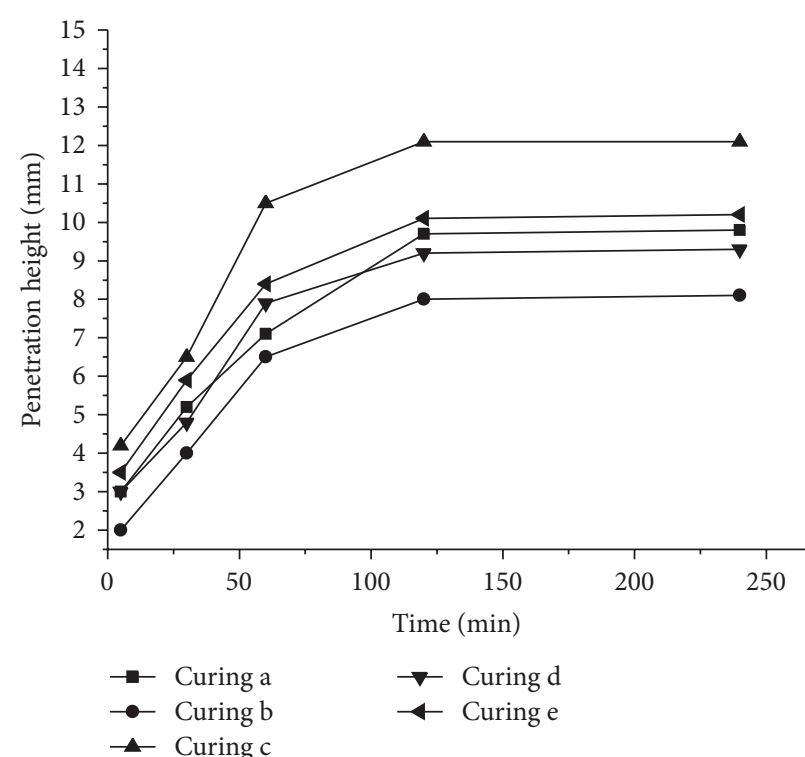

(a)

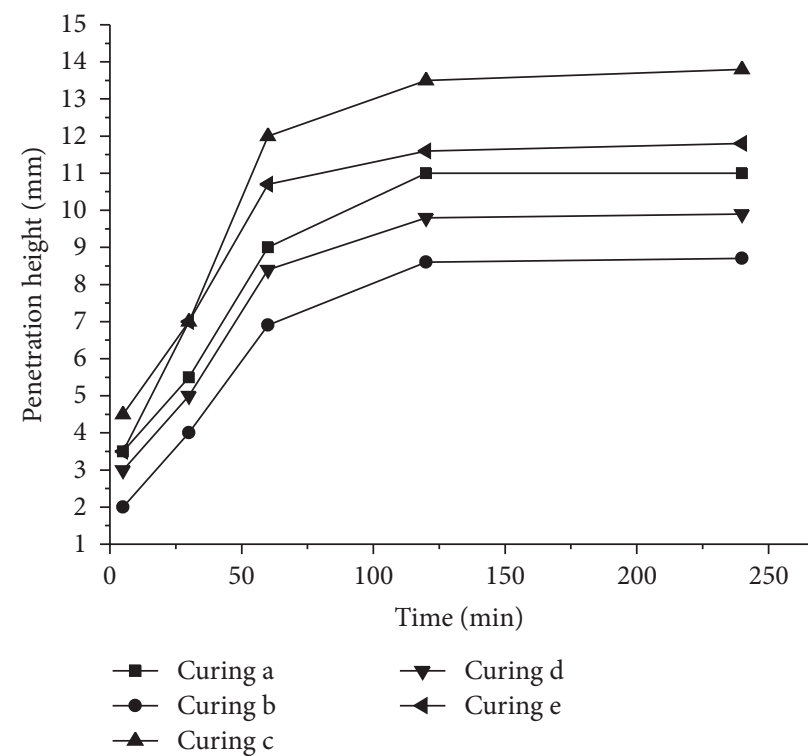

(b)

FIgURE 3: Penetration height of samples: (a) $w / c=0.4$ and (b) $w / c=0.45$.

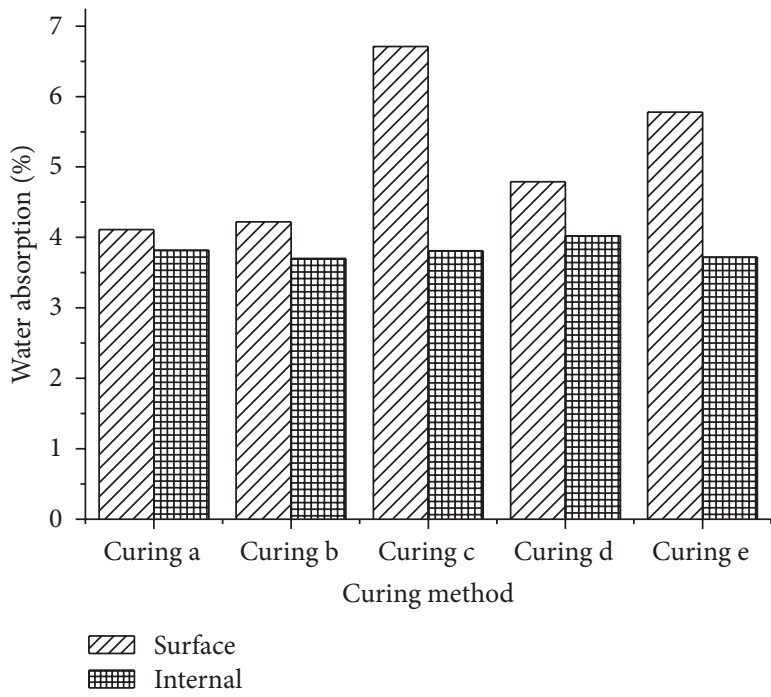

(a)

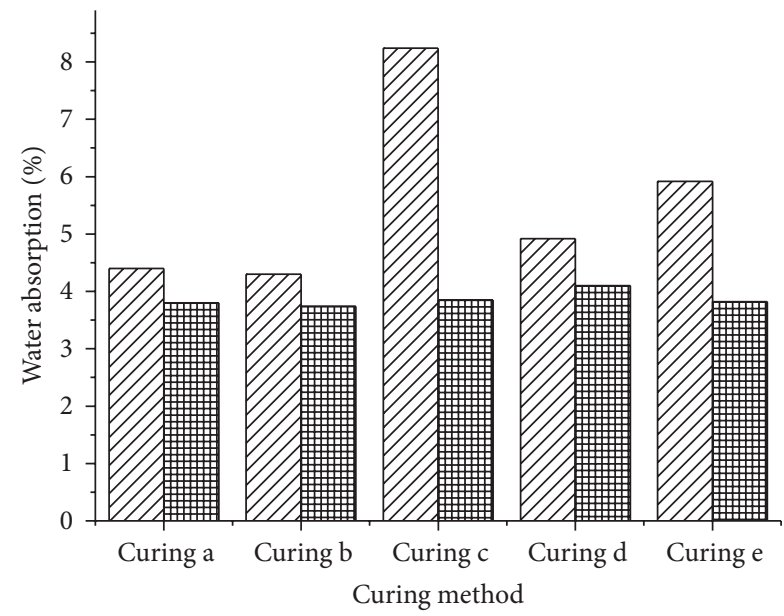

EZJ Surface

Internal

(b)

FIGURE 4: Surface and internal water absorption of samples: (a) $w / c=0.4$ and (b) $w / c=0.45$.

The permeability of concrete was evaluated according to Testing Code of Concrete for Port and Waterwog Engineering (JTJ 270-98). A water pressure of $1.2 \mathrm{MPa} \pm 0.5 \mathrm{MPa}$ was applied on the concrete for $24 \mathrm{~h}$, and then the permeability height was measured by splitting the concrete, as shown in Figure 2 . The permeability coefficient was calculated using

$$
S_{k}=\frac{m D_{m}^{2}}{2 T H},
$$

where $S_{k}$ is the relative permeability coefficient $(\mathrm{mm} / \mathrm{h}), D_{m}$ is the average permeability height $(\mathrm{mm}), m$ is the absorption of the concrete (0.03), $T$ is the testing time (h), and $H$ is the water pressure $(\mathrm{mm})$. Resistance to sulfate attack was evaluated through dry-wet cycle testing. The specimens were kept in sulfate solution for $12 \mathrm{~h}$, then dried at $60^{\circ} \mathrm{C}$ for $12 \mathrm{~h}$, and subsequently placed in sulfate solution for $12 \mathrm{~h}$ in a cycle. Sodium sulfate with concentration of $5 \%$ was used. Compressive strength was measured during testing. 


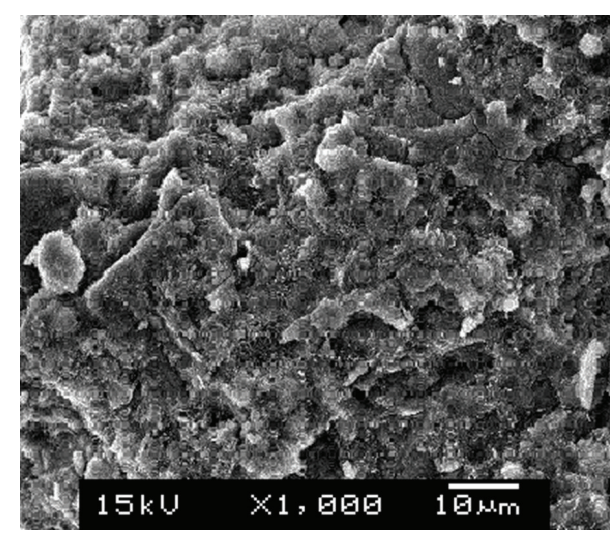

(a)



(b)

FIGURE 5: SEM photos of concrete samples: (a) condition b and (b) condition d.



पID 0.4

0.45

FIGURE 6: Compressive strength of samples.

Rapid migration test is a non-steady state migration using an external electrical field for accelerating chloride penetration. The test is relatively simple and rapid with the test duration in most cases being 24 hours. The concrete samples with size of $100 \mathrm{~mm}$ diameter and $175 \mathrm{~mm}$ thickness were cut into $50 \mathrm{~mm}$ thick slices, from surface and center of samples, respectively. A $30 \mathrm{~V}$ external potential was imposed across the specimen with the test surface exposing in the $10 \% \mathrm{NaCl}$ solution and the oppose surface in the $0.3 \mathrm{M} \mathrm{NaOH}$ solution for a certain duration, then the specimen was splitted, and the penetration depth of chlorides can be measured by using a colourimetric method.

\section{Results and Discussion}

3.1. Water Absorption. Permeability height can be measured through soaking testing, and results about this are given in
Figure 3. It can be shown that penetration height increased apparently with time within $12 \mathrm{~h}$. For different curing methods, penetration height was not the same. In contrast, the samples cured in condition b $\left(20 \pm 3^{\circ} \mathrm{C}, \mathrm{RH} 90 \pm 5 \%\right)$ showed the lowest penetration height, while the samples of Curing c presented the highest one. Samples with lower $w / c$ also showed lower penetration height. It indicated that different curing conditions will cause different permeability of samples.

Sorption depends on both the capillary pressure and effective porosity. Capillary pressure is related to the pore size through the Young-Laplace equation, and effective porosity refers to the pore space in the capillary and gel pores. In addition, different pore size leads to different capillary pressure, and capillary pressure of concrete can be calculated by the average pore size. In order to consider surface effect, both surface water absorption and internal water absorption were investigated. Water absorption is measured by measuring the increase in mass as a percentage of dry mass. Figure 4 gives results of surface and internal water absorption. It can be seen that surface water absorption is higher than internal water absorption for all the specimens. This is due to the rapid loss of water at the cover concrete during curing. As can be expected, higher water absorption corresponds to a higher penetration height. For surface water absorption, results showed that the specimen exposed to air curing $\left(20 \pm 3^{\circ} \mathrm{C}, \mathrm{RH}\right.$ $90 \pm 5 \%$ ) exhibited low water absorption properties compared to other samples. Obviously, air condition $\left(20 \pm 3^{\circ} \mathrm{C}, \mathrm{RH}\right.$ $60 \pm 5 \%)$ caused the highest water absorption. This may be attributed to the higher porosity of the concrete preserved in air $\left(20 \pm 3^{\circ} \mathrm{C}\right.$, RH $\left.60 \pm 5 \%\right)$. Under this curing condition, the surface concrete rapidly loses its water of hydration. On the other hand, for internal water absorption, samples exposed to different curing conditions presented similar results. So, curing methods has great influence on surface properties. For the samples with different $w / c$, it can be seen that surface water absorption of samples with $w / c$ of 0.45 is only slightly higher than that of 0.4 . Furthermore, there was very little difference between both samples for internal water 


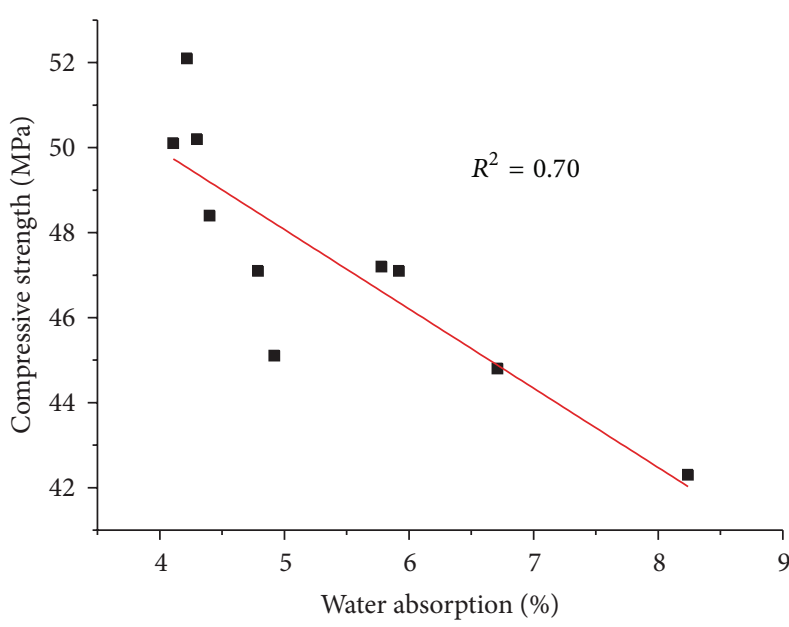

(a)

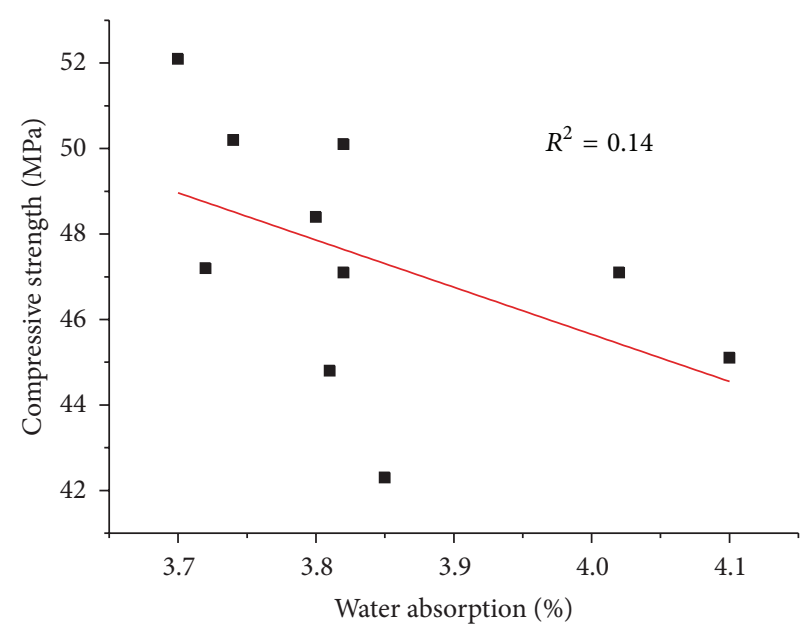

(b)

FIGURE 7: Relationship between water absorption and compressive strength: (a) surface water absorption and (b) internal water absorption.

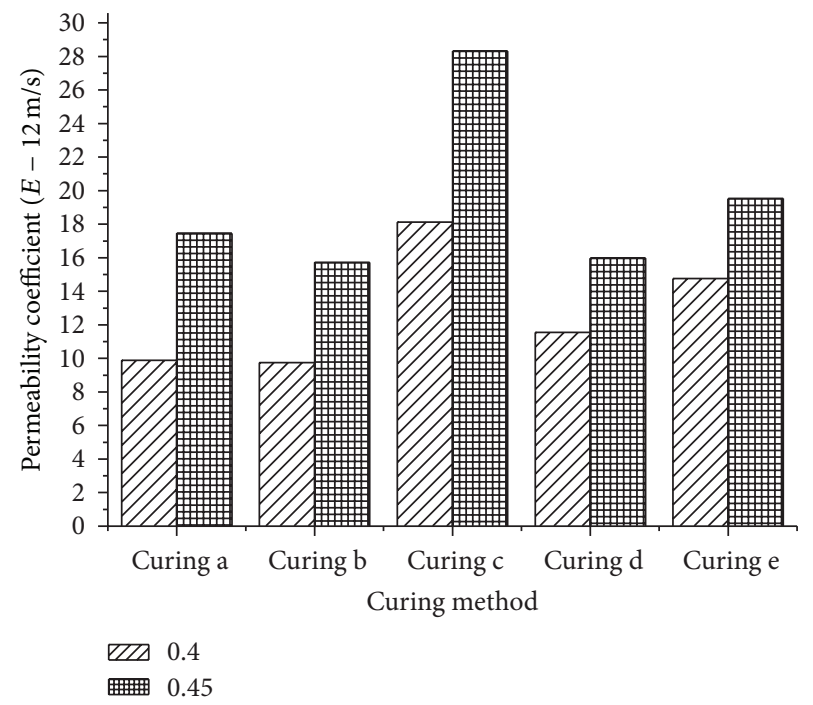

FIGURE 8: Permeability coefficient of samples.

absorption, and $w / c$ seems to have little impact on internal water absorption. In order to investigate the influence of curing on microstructure of concrete, microstructure of concrete samples exposed to different curing conditions was also analyzed by SEM. As there was a large difference in surface water absorption, microstructure of surface concrete was further studied. Figure 5 showed photos of surface concrete obtained by SEM, and Figure 5(a) stands for the sample exposed to condition b, while Figure 5(b) stands for the sample exposed to condition d. From Figure 5, different structures can be seen. For the sample cured in condition $\mathrm{b}$, the microstructure was more compact. However, for the sample cured in condition b, there were holes and loose structure. These are consistent with the results of water absorption.

3.2. Relations between Water Absorption and Compressive Strength. After being cured for 28 days, compressive strength was measured, and Figure 6 presents results of compressive strength. Samples cured in air condition $\left(20 \pm 3^{\circ} \mathrm{C}, \mathrm{RH}\right.$ $90 \pm 5 \%)$ show highest strength, while those cured in air condition $\left(20 \pm 3^{\circ} \mathrm{C}, \mathrm{RH} 60 \pm 5 \%\right)$ have lowest strength. Effects of sorptivity on compressive strength are seen in Figure 7. Figures show that both of surface sorptivity and internal sorptivity have no clear relationship with compressive strength. Although the specimens differ in surface water absorption, there is little difference in internal water absorption. Furthermore, the high surface water absorption only decreased compressive strength of cover concrete. The whole strength of concrete depends on both surface and internal structures. So, strength of concrete cannot be evaluated by water absorption.

3.3. Relations between Water Absorption and Permeability. Permeability coefficients of samples with different curing conditions were measured, and results were given in Figure 8. Relationship between permeability coefficient and water absorption was also analyzed, as shown in Figure 9. From the figures, we can see that there was no clear relationship between permeability coefficient and internal permeability coefficient. However, apparently, a linear correlation exists between permeability coefficient and surface permeability coefficient. The permeability coefficient increased with the increase in surface water absorption. As we know, both of permeability and water absorption were affected by the pore structure of cement paste, and liquid transfers from surface into interior. So, it indicated that surface water absorption provides great influence on permeability. In addition, the high correlation coefficients of 0.90 indicated that there was a significant linear correlation between permeability and 


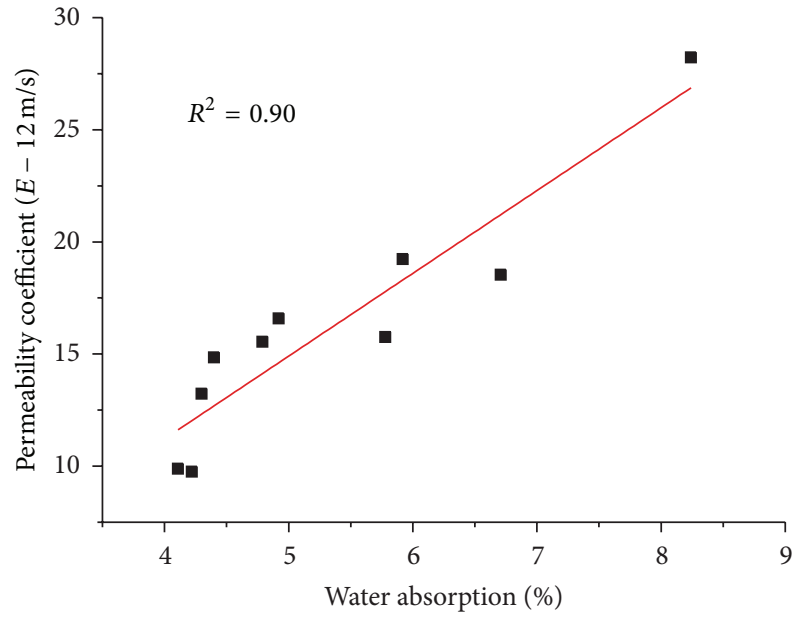

(a)

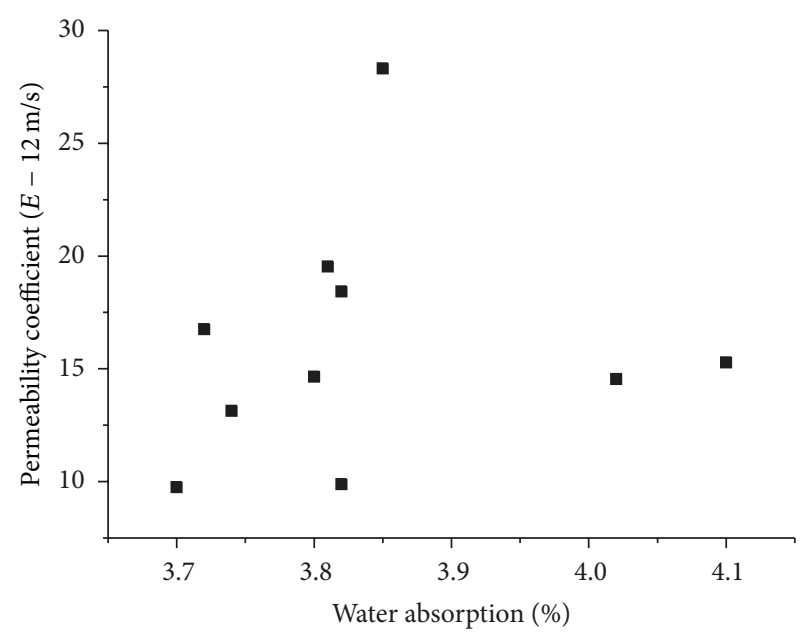

(b)

FIGURE 9: Relationship between water absorption and permeability: (a) surface water absorption and (b) internal water absorption.

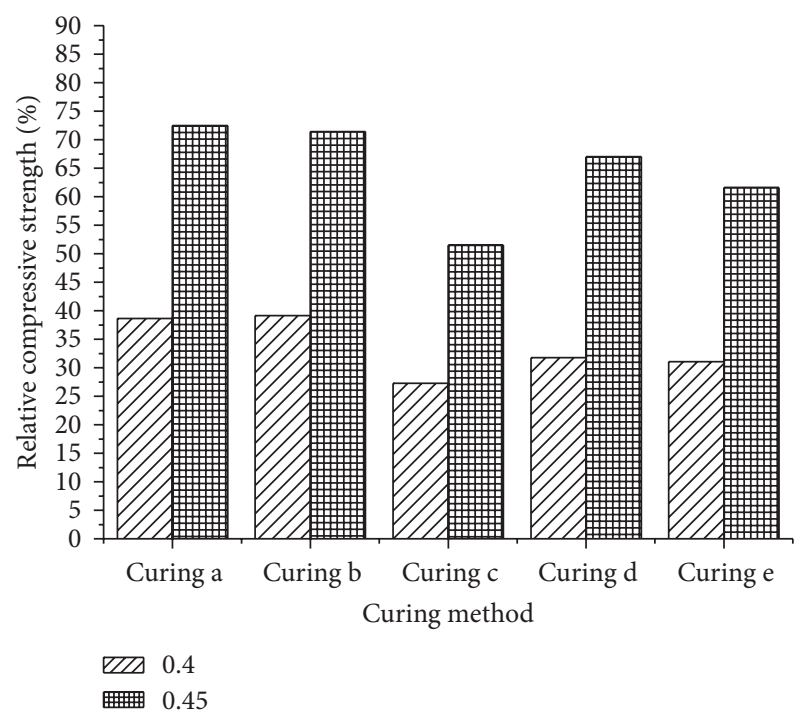

FIGURE 10: Relative strength of samples after sulfate attack.

surface water absorption. In addition, obviously, internal water absorption had little impact on permeability.

3.4. Relations between Water Absorption and Sulfate Attack. Resistance to sulfate attack is evaluated by the loss of strength. During sulfate attack testing, compressive and flexural strengths of specimens were measured after different dry-wet cycles. Relative strengths after 30 dry-wet cycles were presented in Figure 10. Based on Figure 10, it can be seen that compressive strength decreased after sulfate attack, and the sample with $w / c$ of 0.45 showed more loss of strength than that of 0.4 . High $w / c$ led to weaker resistance to sulfate attack. Results shown in Figure 11 demonstrated the effect of water absorption on resistance to sulfate attack. Higher relative strength indicates greater resistance to sulfate attack. It has been discussed earlier that impermeability reduced with the increasing value of surface water absorption. This characteristic was quite similar to the behavior exhibited by resistance to sulfate attack. Based on Figure 11, there was a linear correlation between surface water absorption and loss of compressive strength due to sulfate attack. In addition, loss of compressive strength showed a higher rate of decrement indicated by steep slopes of the curve. By contrast, the loss of compressive strength did not appear to depend upon internal water absorption, as shown in Figure 11(b). The relationships between two parameters were calculated and their correlation results are presented in Figure 11(a).

3.5. Relations between Water Absorption and Chloride Attack. The rapid migration test provides value of $D_{\mathrm{Cl}}$, which is also under the assumption of constant chloride binding capacity during the test. $D_{\mathrm{Cl}}$ was deduced according to (2):

$$
\begin{gathered}
D_{\mathrm{Cl}}=2.872 \times 10^{-6} \frac{T h\left(x_{d}-\alpha \sqrt{x_{d}}\right)}{t}, \\
\alpha=3.338 \times 10^{-3} \sqrt{T h},
\end{gathered}
$$

where $D_{\mathrm{Cl}}$ is chloride ion diffusion coefficient, $\mathrm{m}^{2} / \mathrm{s} ; T$ is average value of early and final temperature of anolyte, $\mathrm{K} ; h$ is the height of the sample, $\mathrm{m} ; x_{d}$ is the diffusion depth of chloride ion, $\mathrm{m} ; t$ is the testing time, $\mathrm{s} ; \alpha$ is auxiliary variable.

Capillary absorption is an important mechanism related to the chloride ingress into concrete. Nonsaturated concrete in contact with a salt solution will absorb this solution by capillary forces [16]. Figure 12 gives the chloride ion diffusion coefficient $D_{\mathrm{Cl}}$ of concrete. From Figure 12, for $w / c$ of 0.4 , the chloride ion diffusion coefficient was lower, and this may be due to the higher water absorption of concrete whose $w / c$ was 0.45 . Figure 13 shows relationship between water absorption and chloride ion diffusion coefficient. Based on 


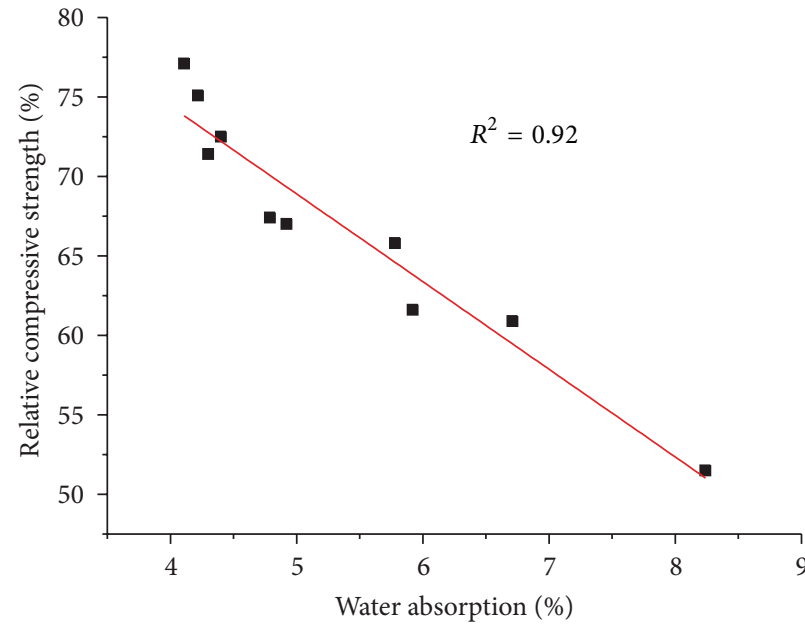

(a)



(b)

FIGURE 11: Relationship between water absorption and resistance to sulfate attack: (a) surface water absorption and (b) internal water absorption.

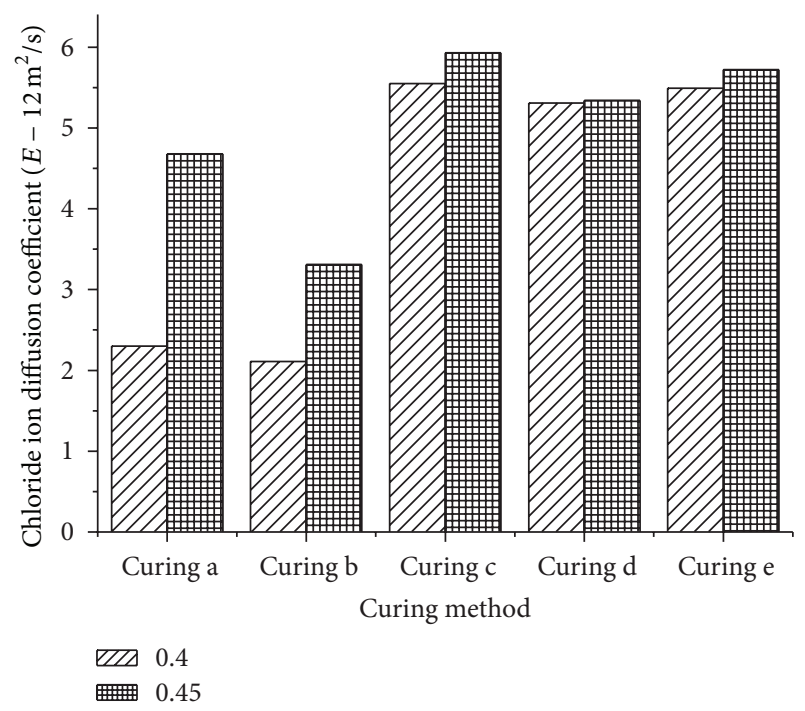

Figure 12: Chloride ion diffusion coefficient of samples.

the results, it can be seen that chloride ion diffusion coefficient related to water absorption surface concrete, and chloride ion diffusion coefficient increased with the water absorption. The sample with lowest absorption still showed the best resistance to chloride ion diffusion. Unlike previous results, chloride ion diffusion coefficient has exponent relation to water absorption, and the correlation coefficient is 0.91 . The simultaneous action of diffusion and capillary suction thus causes a mixed transport mode. Once chloride penetrated, the initial mechanism appears to be suction when the surface is dry and chloride solution is rapidly absorbed by dry concrete. Next, diffusion dominated transport mechanism, instead of capillary movement of chloride solution. Both of these two kinds of mechanism depended on pore structure, which was evaluated by water absorption here.

\section{Conclusions}

Based on the results and the discussion of mechanical performance, permeability, sulfate attack, and chloride ion diffusion of the concrete with different water absorption, the following conclusions are drawn.

Curing conditions can greatly affect the water absorption of concrete. Based on the curing conditions in this paper, the concrete which was exposed to air curing $\left(20 \pm 3^{\circ} \mathrm{C}\right.$, RH $90 \pm 5 \%$ ) exhibited low water absorption. In addition, surface water absorption was higher than internal water absorption regardless of curing conditions. Both of surface water absorption and internal water absorption had no clear relationship with compressive strength, which indicated that the strength cannot be simply evaluated by water absorption. Permeability mainly depended on the surface water absorption of concrete, and there was a significant linear correlation between permeability and surface water absorption. However, internal water absorption presented little relationships to permeability. Higher water absorption decreased resistance to sulfate attack of concrete, and the relationship between surface water absorption and resistance to sulfate attack was approximately linear. Similarly, it presented a poor correlation between internal water absorption and resistance to sulfate attack. Furthermore, chloride ion diffusion coefficient has exponent relation to surface water absorption, and the correlation coefficient is 0.91 . As a whole, surface water absorption can be applied to predict some performance of concrete, including compressive strength, permeability, resistance to sulfate attack, and chloride ion diffusion. 


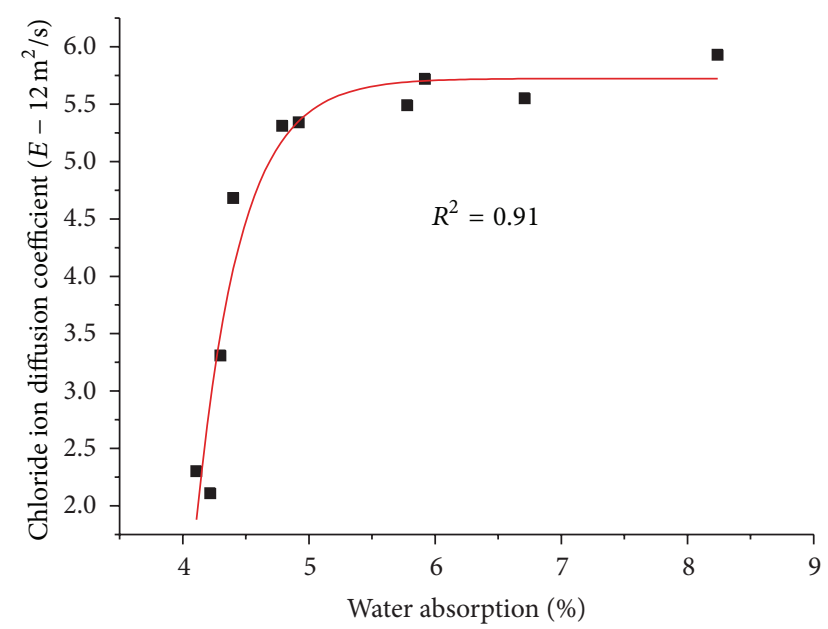

(a)

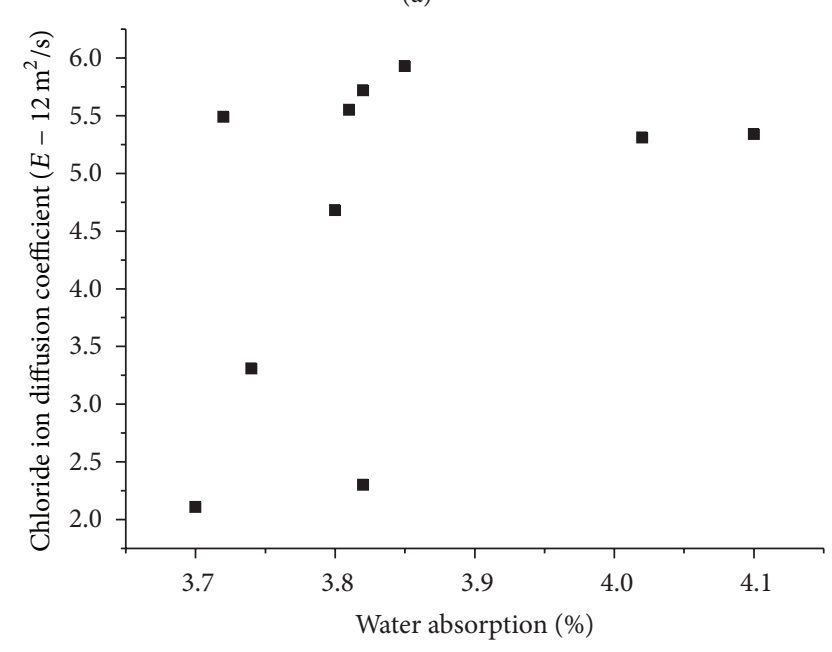

(b)

FIGURE 13: (a) Surface water absorption, and (b) internal water absorption.

\section{Conflict of Interests}

The authors declare no conflict of interests.

\section{Acknowledgments}

This research was supported by the National Natural Science Foundation of China (no. 51108231), Science and Technology Plan Projects of Ministry of Housing and Urban-Rural Development of China (Grant no. 2013-K4-20), and Project of Young Academic Backbone Teachers of Nanjing Institute of Technology.

\section{References}

[1] P. K. Mehta and P. J. M. Monteiro, Concrete: Microstructure, Properties and Materials, McGraw-Hill, NewYork, NY, USA, 2006.
[2] A. Alhozaimy, P. Soroushian, and F. Mirza, "Effects of curing conditions and age on chloride permeability of fly ash mortar," ACI Materials Journal, vol. 93, no. 1, pp. 87-95, 1996.

[3] G. De Schutter and K. Audenaert, "Evaluation of water absorption of concrete as a measure for resistance against carbonation and chloride migration," Materials and Structures, vol. 37, no. 273, pp. 591-596, 2004.

[4] M. Ramli and A. A. Tabassi, "Effects of polymer modification on the permeability of cement mortars under different curing conditions: a correlational study that includes pore distributions, water absorption and compressive strength," Construction and Building Materials, vol. 28, no. 1, pp. 561-570, 2012.

[5] N. Shafiq and J. G. Cabrera, "Effects of initial curing condition on the fluid transport properties in OPC and fly ash blended cement concrete," Cement and Concrete Composites, vol. 26, no. 4, pp. 381-387, 2004.

[6] K. E. Hassan, J. G. Cabrera, and Y. M. Bajracharya, "The influence of fly ash content and curing temperature on the properties of high performance concrete," in Proceedings of the 5th International Conference, Deterioration and Repair of Reinforced Concrete in the Arabian Gulf, Bahrain, pp. 311-319, 1997.

[7] C. Tasdemir, "Combined effects of mineral admixtures and curing conditions on the sorptivity coefficient of concrete," Cement and Concrete Research, vol. 33, no. 10, pp. 1637-1642, 2003.

[8] W. P. S. Dias, "Reduction of concrete sorptivity with age through carbonation," Cement and Concrete Research, vol. 30, no. 8, pp. 1255-1261, 2000.

[9] C. Hall, "Water sorptivity of mortars and concretes: a review," Magazine of Concrete Research, vol. 41, no. 147, pp. 51-61, 1989.

[10] P. Mohr, Mechanisms of improved transport phenomena in mature portland cement pavements: a macro and microstructureal evaluation [Ph.D. thesis], University of Michigan, Ann Arbor, Mich, USA, 2004.

[11] N. S. Martys and C. F. Ferraris, "Capillary transport in mortars and concrete," Cement and Concrete Research, vol. 27, no. 5, pp. 747-760, 1997.

[12] C. Tasdemir, "Combined effects of mineral admixtures and curing conditions on the sorptivity coefficient of concrete," Cement and Concrete Research, vol. 33, no. 10, pp. 1637-1642, 2003.

[13] R. P. Khatri, V. Sirivivatnanon, and L. K. Yu, "Effect of curing on water permeability of concretes prepared with normal Portland cement and with slag and silica fume," Magazine of Concrete Research, vol. 49, no. 180, pp. 167-172, 1997.

[14] S. Kelham, "A water absorption test for concrete," Magazine of Concrete Research, vol. 40, no. 143, pp. 106-110, 1988.

[15] M. Kaviany, Principles of Heat Transfer in Porous Media, Springer, New York, NY, USA, 1995.

[16] J. Kropp, H. K. Hilsdorf, H. Grube, C. Andrade, and L. Nilsson, "Transport mechanisms and definitionseditors," in Performance Criteria for Concrete Durability, J. Kropp and H. K. Hilsdorf, Eds., pp. 4-14, E and FN Spon, London, UK, 1995. 



Submit your manuscripts at http://www.hindawi.com
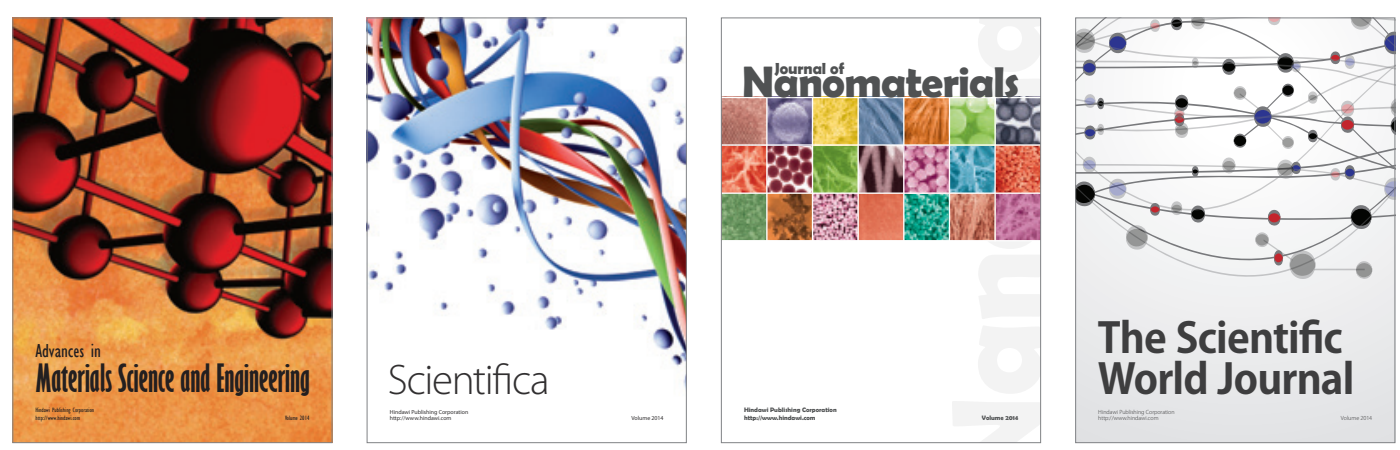

\section{The Scientific World Journal}
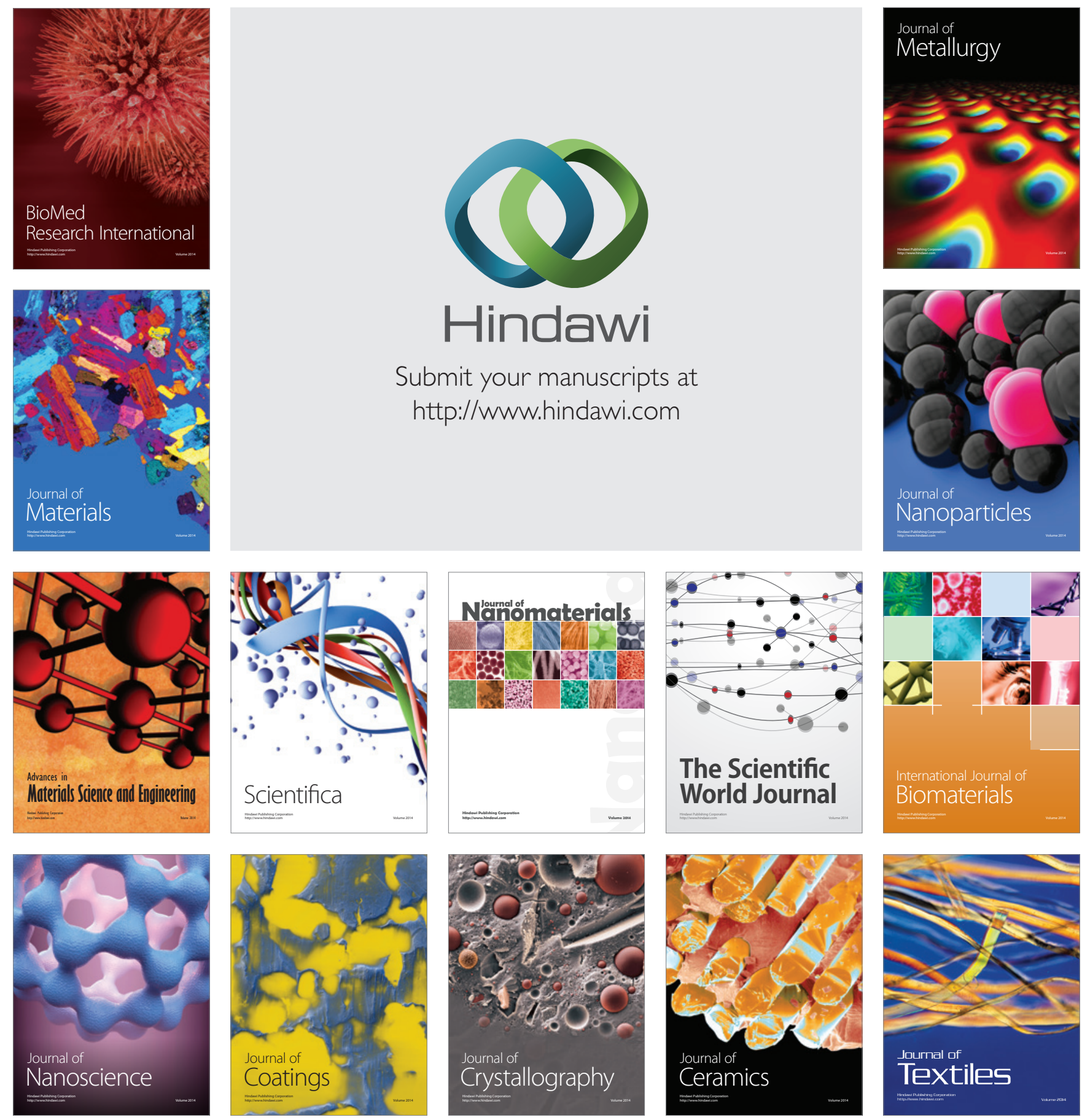